\title{
COVID-19 ve palyatif bakım
}

\section{COVID-19 and palliative care}

\author{
(ㄴ)Nida Aydın \\ Yakın Doğu Üniversitesi Hemşirelik Fakültesi, Lefkoşa, KKTC
}

Cite this article as / Bu makaleye atıf için: Aydın N. COVID-19 ve palyatif bakım. J Med Palliat Care 2021; 2(2): 54-57.

\begin{abstract}
ÖZ
Pozitif vaka ve ölüm oranlarının arttığı COVID-19 pandemisinde, tıbbi tedaviye duyulan ihtiyacın, sağlık sistemi ve özellikle de yoğun bakım ünitesi kapasitesini aşması beklenmektedir. Sağlık çalışanları, hayatta kalma şansı daha yüksek olan hastalar için yoğun bakım ünitesi bakımına ve ventilatör desteğine öncelik verme konusunda zor etik kararlarla karşı karşıyadır. Palyatif bakımın COVID-19 pandemi planlamasına entegrasyonu, sağlık hizmeti sağlayıcılarını öngörülemeyen durumlara hazırlanmak ve gereken kaynaklarla donatmak için önemlidir. Pandemi sırasında palyatif bakımın rolünü inceleyen araştırmalar, hastane ortamında yeni palyatif bakım modelleri geliştirmek için stratejilere odaklanmıştır. Sınırlı kaynaklar ile bakım, yararlı olmayan tedavinin durdurulması, semptom kontrolü ve palyatif müdahaleler, palyatif bakım sunum yöntemleri, ölüm ve yas desteği gibi konularda ihtiyaçlar doğrultusunda kılavuzlara ihtiyaç duyulmaktadır.
\end{abstract}

Anahtar Kelimeler: COVID-19, palyatif bakım, yoğun bakım

\begin{abstract}
In the COVID-19 pandemic, where positive case and mortality rates have increased, the need for medical treatment is expected to exceed the capacity of the health system and especially the intensive care unit. Healthcare professionals are faced with difficult ethical decisions to prioritize intensive care unit care and ventilator support for patients with a higher chance of survival. The integration of palliative care into COVID-19 pandemic planning is crucial to preparing and equipping healthcare providers for unforeseen situations. Research examining the role of palliative care during the pandemic has focused on strategies for developing new palliative care models in the hospital setting. Guidelines are needed in line with the needs in subjects such as care with limited resources, withholding non-beneficial treatment, symptom control and palliative interventions, palliative care delivery methods, death and bereavement support.
\end{abstract}

Keywords: COVID-19, palliative care, critical care

\section{GİRIŞ}

Yeni tip koronavirüs (SARS-CoV-2) kaynaklı COVID-19 enfeksiyonu, Çin'in Wuhan kentinde Aralık 2019 sonlarında ortaya çıkmıştır. Yüksek bulaşma özelliği gösteren virüs kısa sürede dünyaya hızlı bir şekilde yayılmış ve Dünya Sağlık Örgütü (DSÖ) tarafindan Mart 2020'de pandemi ilan edilmiştir $(1,2)$. Her gün pozitif vaka ve ölüm oranlarının arttığı COVID-19 pandemisinde 14 Şubat 2021 tarihi itibariyle dünyada; 108.006 .680 vaka görülmüş ve 2.378 .115 ölüm gerçekleşmiştir $(3,4)$. COVID-19 tanısı alan hastaların çoğu asemptomatiktir ya da hafif semptomlara sahiptir. Bununla birlikte hastaların \%5'inin hastanede tedavi alması gerekirken, \%1-2'sinin yoğun bakım ünitesi (YBÜ) yatışına ve ventilatör desteğine ihtiyaçları vardır (5). Yaşlılarda, kronik hastalığı bulunanlarda ve malignitesi olan hastalarda ölüm oranlarının yüksek olduğu görülmektedir (6). Dünyada artan COVID-19'lu hasta sayısının ve buna bağlı tıbbi tedaviye duyulan ihtiyacın, sağlık sisteminin, özellikle de YBÜ yataklarının ve ventilatörlerin kapasitesini aşması beklenmektedir. Sağlık çalışanları, hayatta kalma şansı daha yüksek olan hastalar için YBÜ bakımına ve ventilatör desteğine öncelik verme konusunda zor etik kararlarla karşı karşıyadır (7). Ayrıca tedavisi YBÜ'lerde devam eden ve palyatif bakım ekiplerince yaşam sonu bakımı alan hastalar, COVID-19 pandemisinden sonra sağllk hizmetlerinin ve sınırlı kaynakların paylaşılması ve bakım ortamlarında bulaș riskiyle karșılaşmıșlardır (8). 
Dünya Sağlık Örgütü (DSÖ) palyatif bakımı; "Yaşamı tehdit eden hastalığa bağlı ortaya çıkan problemlerle karşılaşan yetişkin ve pediatrik hastalarda ve ailelerinde; ağrının ve diğer problemlerin giderilmesi, erken tanılama ve kusursuz bir değerlendirme ile fiziksel, psikososyal ve spiritüel gereksinimlerin karşılanması, acı çekmenin önlenmesi ve hafifletilmesine yönelik uygulamaların yer aldığı ve yaşam kalitesini geliştirmenin amaçlandığ bir yaklaşımdır” șeklinde tanımlamaktadır (9). Palyatif bakım yalnızca hastanın değil hasta yakınlarının da ihtiyacına göre, her iki grubun da hayat kalitesini artırmak üzerine şekillenmektedir. Palyatif bakım doktorların, hemşirelerin, hasta bakım personellerinin, sosyal hizmet uzmanlarının ve hastane yönetiminin multidisipliner bir çerçevede, koordineli bir şekilde çalışmasını gerektirmektedir (10).

Palyatif bakımın COVID-19 pandemi planlamasina entegrasyonu, sağlı hizmeti sağlayıcılarını öngörülemeyen durumlara hazırlanmak ve gereken kaynaklarla donatmak için çok önemlidir. $(7,8)$. Pandemi sırasında palyatif bakımın rolünü inceleyen araştırmalar, hastane ortamında yeni palyatif bakım modelleri geliştirmek için stratejilere odaklanmıştır $(7,11)$.

\section{Sınırlı Kaynaklar ile Bakım}

Yoğun bakımlarda bulunan mevcut ventilatör ve kaynaklar dikkate alındığında, sağlık sisteminin solunum yetmezliği yaşayan herkes için yeterli desteği sağlayamayacağ sağlayıcıların, müdahalelerden yararlanma olasılığ daha yüksek olan hastalar için YBÜ bakımı ve ventilatör desteği önceliği konusunda karar verme zorunda kalacağı düşünülmektedir (7). Ölüm oranlarının yaş ve etkilenen organ sayısı ile $\operatorname{arttığ~}$ açık olsa da, karar vermede yardımcı olabilecek sınırlı bilimsel veri bulunmaktadır. Bu durum hasta otonomisine, küratif tedaviye ve yaşamı uzatmak için teknolojik gelişmelere vurgu yapan sağlık sisteminde kararların alınmasında büyük bir belirsizliğe yol açacaktır. COVID-19 tarafından empoze edilen ikilem, sağlık çalışanlarının bakımın önceliklendirilmesini ele alma biçiminde bir paradigma değişikliği yaratacaktır. YBÜ ihtiyaci olan ve tedavisi YBÜ'de devam edecek olan hastaları belirleme kararını desteklemek için yerel olarak uygulanabilir kılavuzlara ihtiyaç vardır. Birçok Avrupa toplumu, sağlık hizmeti sağlayıcılarına tedaviyi sınırlandırma kararları vermede yardımcı olmak için kriterler yayınlamıştır $(7,8)$. Bu kriterler olanakların en fazla sayıda kişiye ulaşmasına imkan sağlayan faydacılık etik ilkesine dayanmaktadır. Sağlık hizmetleri sistemleri, etik ilkeleri kullanarak kendi yerel yönergelerini geliştirmeli ve bilimsel araştırmalar ışığında güncel tutmalıdırlar $(7,12)$.

\section{Yararlı Olmayan Tedavinin Durdurulması}

Wuhan ve Washington Eyaleti raporlarına göre entübasyon ve mekanik ventilasyon gerektiren COVID-19 hastalarında \%86'ya varan ölüm oranları yaşandığını görülmektedir $(13,14)$. Yüksek ölüm oranları göz önüne alındığında, birçok yaşlı ve ilerlemiş kronik problemi olan hastanın entübasyon ve mekanik ventilasyonu yaşam sonu bakım ilkesiyle uyuşmamaktadır. İnvaziv müdahalelerin fayda sağlamaktan çok zarara ve rahatsızlığa neden olma ihtimalinin yüksek olduğu durumlarda, zarar vermeme etik ilkesi uygulanabilir. Yaşam kalitesine yaşamın uzunluğundan daha çok önem veren hastalarda, yararlı olmayan tedavinin durdurulması kararında sağlık hizmeti sağlayıcılarına yardımcı olabilecek çerçevelerin oluşturulması ihtiyaçtır (7).

\section{Semptom Kontrolï ve Palyatif Müdahaleler}

Yaşam sonu bakımı alan hastaların yaşadığı dispne, ağrı ve deliryum gibi semptomların etkili bir şekilde kontrol altına alınması gerekmektedir. Bu durum YBÜ tedavisine ihtiyaç duyan hasta sayısını azaltacağ palyatif bakımın amaçlarından olan yaşam kalitesini de artıracaktır. Yetersiz semptom kontrolü, dispne için noninvazif mekanik ventilasyon, ajite veya deliryumdaki hastalar için fiziksel sınırlayıcıların yerleştirilmesi gibi gereksinimler sağlık çalışanlarına hastalık bulaşma riskini artırabilecek müdahalelere neden olabilir. Semptom kontrolünün uygun şekilde yapılması hastaları rahatlamasına katkı sağlarken, sağlık ekip üyeleri ve hasta yakınlarının da tükenmişlik ve merhamet yorgunluğunu ortadan kaldıracaktır. Semptom kontrolü konusunda sağlık çalışanlarının eğitiminin gerekliliği vurgulanmaktadır (15).

COVID-19 hastalarında yoğun bakım yaklaşımı ve palyatif bakım yaklaşımı birkaç farklılık göstermektedir. YBÜ'de bakım alan COVID-19'lu bireylerin mortalite oranlarının yüksek olması nedeniyle hastaların bakımına her iki yaklaşımında entegre edilmesi önemlidir (7).

Palyatif bakım planlamasına dahil edilmesi gereken önemli bir diğer husus ise, her gün kayıplarla karşılaşan sağlık hizmeti sağlayıcılarına verilmesi gereken destektir. Bulaş ve ölüm oranlarının yüksek olduğu sağlık çalışanları meslek grubunun, meslektaşlarının tedavi ve bakımını yapmaları ve ölümlerine tanık olmaları, yaşadıkları sorunları ve tükenmişliklerini artırmaktadır $(7,16)$.

\section{Palyatif Bakım Sunum Yöntemleri}

COVID-19 pandemisi, yaşam sonu bakıma ihtiyaç duyan hastalarda palyatif bakım hizmetleri kapasitesini aşabilecek șekilde artışa neden olmaktadır. Palyatif bakım programlarının, palyatif bakım ekip üyelerinin sağlığını korurken, bu artışla başa çıkabilecek şekilde hazırlanması gerekmektedir. Palyatif bakım sağlayıcılarının etkili 
semptom kontrolü ve iletişim stratejileri konusunda birincil ekipleri eğitmede liderlik etmelerinin önemi vurgulanmaktadır. Pandeminin ortaya çıkardığ 1 bir başka zorluk, bütüncül interdisipliner palyatif bakımın etkili bir şekilde sağlanmasını olumsuz etkileyebilecek izolasyon ve sosyal mesafe prosedürleridir (7). Özellikle sağlık hizmetlerinin kişisel koruyucu ekipman gibi sınırlı kaynakları korumaya çalıştığ ve bu nedenle hastanın odasına girebilecek personel sayısının sinırlandırılması bakımda olumsuz etkilere yol açmaktadır. Palyatifbakımın sağlanmasında, teletıp, teledanışmanlık kullanımına ilişkin kanıtlar ve öneriler sunulmaktadır. Teletıp; hastalar, aileler ve bakım sağlayıcılar arasında COVID-19 bulaşını azaltmaya çalışırken, hastalara tıbbi bakım sağlamak için kritik bir teknoloji olarak fayda sağlamaktadır (17). Ancak akut bakım ortamında etkili bir şekilde uygulamak için yeterli hazırlık ve teknik uzmanlığa ihtiyaç duyulması, bazı teknolojikzorluklarvehastaların teknoloji okuryazarlığının değişiklik göstermesi göz ardı edilmemelidir. Palyatif bakım ekiplerinin hastalara ve ailelere hizmet sunmak için en uygun platformu belirleme, uygulama ve eğitim konusunda proaktif olmaları gerekecektir $(7,17)$.

\section{Ölüm ve Yas Desteği}

COVID-19'dan hasta ya da hasta yakını olarak etkilenen bireylerde ölüm ve yas sürecinde çeşitli sorunlar ortaya çıabilir. Yoğun bakım sürecinde hasta ziyaretlerinin tamamen yasak olması nedeniyle bu kritik dönemde sevdikleriyle birlikte olamayan hasta yakınları, belirsizlik ve endişe içinde yüksek risk altındadır. Yoğun bakım ortamında tek başına kalmak ve tek başına ölmek hastalar ve yakınları için zordur. Ölümden sonra enfeksiyonun yayılmasını önlemek için cenazenin özel bir şekilde ele alınması gerekecektir. Cenazenin görülememesi, dini ritüellerin ve geleneklerin yerine getirilememesi, cenazenin gömülmesi sırasında bulaşmayı önlemek için bazı uygulamaların pandemi öncesi rutinlerinin dı̧sında sağlık açısından uygun şekilde yapılması gerekliliği hasta yakınları için kaybı kabullenmelerinde güçlük yaşamalarına sebep olabilecektir. Tüm bu gereksinimler, kendilerinin de karantinaya alınma ihtimali olan hasta yakınları için yas sürecini daha da karmaşık hale getirecektir. Bu kişilerin izlemi ve erken dönem yas danışmanlığı verilmesi koruyucu olabilir. Yas danışmanlığı sunmaya yönelik müdahaleler, çevrimiçi ve sanal gerçekliğe dayalı yöntemleri içermelidir. Bu sosyal izolasyon zamanlarında, sanal destek grupları kederli aile üyelerine deneyimlerini paylaşma ve umut bulma konusunda yardımcı olabilir. $(7,18,19)$.

\section{SONUÇ}

COVID-19 pandemisinin sağllk hizmetleri sisteminin kapasitesini aşması ile pandemi planlamasında palyatif bakımın entegrasyonuna ihtiyaç duyulmaktadır. Sağlık hizmeti sağlayıcılarının palyatif bakım ilkeleri ve kaynaklar doğrultusunda hastalara nasıl triyaj yapılacağı konusunda eğitimi ile güncel ve yerel kılavuzlara gereksinim vardır. Palyatif bakım sağlanması için teknolojik yöntemler, teletıp, tele-danışmanlık ve çevrimiçi yas destek grupları gibi alternatif yöntemler kullanılabilir. Pandemi sırasında palyatif bakımın kanıta dayalı uygulamalar ile yapılabilmesi için COVID-19'a ilișkin verilerin, araștırma sonuçlarının belgelemesi gerekmektedir. Ayrıca, sağlık hizmeti sağlayıcıları için yenilikçi bakım eğitimlerine ihtiyaç vardır.

\section{ETİK BEYANLAR}

Hakem Değerlendirme Süreci: Harici çift kör hakem değerlendirmesi.

Çıkar Çatışması Durumu: Yazarlar bu çalışmada herhangi bir çıkara dayalı ilişki olmadığını beyan etmişlerdir.

Finansal Destek: Yazarlar bu çalışmada finansal destek almadıklarını beyan etmişlerdir.

Yazar Katkıları: Yazarların tümü; makalenin tasarımına, yürütülmesine, analizine katıldığını ve son sürümünü onayladıklarını beyan etmişlerdir.

\section{KAYNAKLAR}

1. Jiang F, Deng L, Zhang L, Cai Y, Cheung CW, Xia Z. Review of the clinical characteristics of coronavirus disease 2019 (COVID-19). J Gen Intern Med 2020; 35: 1545-9.

2. Zhu J, Ji P, Pang J, et al. Clinical characteristics of 3062 COVID-19 patients: A meta-analysis. J Med Virol 2020; 92: 1902-194.

3. World Health Organization. WHO Coronavirus Disease (COVID-19) Dashboard, https://covid19.who.int/, Erişim Tarihi:14.02.2021.

4. World Health Organization (WHO), Integrating palliative care and symptom relief into primary health care: a WHO guide for planners, implementers and managers. Geneva: 2018, https:// apps.who.int/iris/handle/10665/274559, Erişim Tarihi: 30.01.2021

5. Mizumoto K, Kagaya K, Zarebski A, Chowell G. Estimating the asymptomatic proportion of coronavirus disease 2019 (COVID-19) cases on board the diamond Princess cruise SHIP, Yokohama, Japan, 2020. Euro Surveill 2020; 25. doi:10.2807/15607917.ES.2020.25.10.2000180

6. Wu C, Chen X, Cai Y, et al. Risk factors associated with acute respiratory distress syndrome and death in patients with coronavirus disease 2019 pneumonia in Wuhan, China. JAMA Intern Med 2020; 180: 934-43.

7. Fadul N, Elsayem AF, Bruera E. Integration of palliative care into COVID-19 pandemic planning. BMJ Support Palliat Care. doi:10.1136/bmjspcare-2020-002364

8. Borasio GD, Gamondi C, Obrist M, Jox R. COVID-19: decision making and palliative care. Swiss Med Wkly 2020; 150: w20233. doi:10.4414/smw.2020.20233

9. WHO definition of palliative care, http://www.who.int/cancer/ palliative/definition/en/, Erişim tarihi: 12.01.2021

10. Özçelik S. Palyatif bakıma bakış ve hemşireliğin rolü. J Med Palliat Care 2020; 1: 76-82. 
11. Sheehan J, Ho KS, Poon J, Sarosky K, Fung JY. Palliative care in critically ill COVID-19 patients: the early New York City experience. BMJ Support Palliat Care 2020. doi:10.1136/ bmjspcare-2020-002677

12. Maves RC, Downar J, Dichter JR, et al. Triage of scarce critical care resources in COVID-19 an implementation guide for regional allocation: an expert panel report of the task force for mass critical care and the American College of chest physicians. Chest 2020. doi:10.1016/j.chest.2020.03.063.

13. Yang X, Yu Y, Xu J, et al. Clinical course and outcomes of critically ill patients with SARS-CoV-2 pneumonia in Wuhan, China: a single-centered, retrospective, observational study. Lancet Respir Med 2020; 8: 475-81.

14. Bhatraju PK, Ghassemieh BJ, Nichols M, et al. COVID-19 in critically ill patients in the Seattle Region - Case series. N Engl J Med 2020; 382: 2012-22.

15. Hendin A, La Rivière CG, Williscroft DM, O'Connor E, Hugles J, Fischer LM. End-of-life care in the emergency department for the patient imminently dying of a highly transmissible acute respiratory infection (such as COVID-19). CJEM 2020:1-4.

16. Arpacıoğlu S, Baltalı Z, Ünübol, B. COVID-19 pandemisinde sağlık çalışanlarında tükenmişlik, Covid korkusu, depresyon, mesleki doyum düzeyleri ve ilişkili faktörler. Cukurova Med J 2021; 46: 88-100.

17. Calton B, Abedini N, Fratkin M. Telemedicine in the time of coronavirus. J Pain Symptom Manage 2020; 60: 12-4.

18. Çelik F, Gündüz N. COVID-19 pandemisinde Yas. Klinik Psikiyatri Derg 2020; 23: 99-102.

19. Savaş E. COVID-19 sürecinde yas. Türkiye Sosyal Hizmet Araştırmaları Derg 2020; 4: 82-9. 